\title{
Patellofemoral pain during adolescence: much more prevalent than appreciated
}

\author{
M S Rathleff ${ }^{1,2}$
}

\section{PATELLOFEMORAL PAIN IS COMMON AMONG ADOLESCENTS}

Musculoskeletal conditions are not unique to the adult population. From the age of $5-9$ years to the age of $10-14$ years there is an almost fourfold increase in the years lived with disability as a result of musculoskeletal conditions. ${ }^{1}$ In Danish primary care, we see an eightfold increase in the number of contacts to general practice because of knee symptoms between 5-9 and 10-19 years. ${ }^{2}$ This makes knee pain one of the most common sites of pain in adolescents. ${ }^{3}$ Our research shows that $6-7 \%$ of the adolescent population is affected (in varying severities) by patellofemoral pain (PFP). ${ }^{4} 5$ This makes PFP one of the most common knee conditions among adolescents.

Depending on how you define adolescence and adulthood, more than 95\% of all research on PFP is carried out on adults. This does not match the high prevalence among adolescents. It is appreciated that children are not small adultsadolescents appear to need their own attention too.

\section{WHO ARE THE ADOLESCENTS WITH PFP?}

PFP is highly prevalent in people who do a lot of sports. In adolescent female basketball players, it may be as high as $16 \%$. $^{6}$ In our population-based study, two-thirds of the adolescents with PFP were highly active and engaged in sport, on average five times per week (even with knee pain!) But there was also a subgroup $(\sim 1 / 3)$ who did not do any sports at all. This is important, and challenges the common notion that PFP is always a loaddependent condition associated with sports. ${ }^{7}$ However, the high prevalence in sports population suggests that highly repetitive and/or excessive and specific loading contributes to the pathogenesis of PFP in adolescents.

\footnotetext{
${ }^{1}$ Research Unit for General Practice in Aalborg and Department of Clinical Medicine, Aalborg University, Aalborg, Denmark; ${ }^{2}$ Department of Occupational Therapy and Physiotherapy, Aalborg University Hospital, Aalborg, Denmark

Correspondence to Dr M S Rathleff, Fyrkildevej 7, 1,
} Aalborg East 9220, Denmark; misr@hst.aau.dk

\section{IS ADOLESCENT PFP 'SELF-LIMITING'?}

A common notion is that knee pain and PFP is a natural part of adolescence and is self-limiting. We recently made a follow-up of 153 adolescents with PFP for 2 years and $65 \%$ of them still had knee pain after a 2-year follow-up and a quarter of them reported they had daily knee pain. ${ }^{8}$ Importantly, a large proportion of the adolescents with PFP stopped or reduced their sports participation during the 2 yearsPFP can impair the overall health. These findings extend previous retrospective long-term follow-up studies on adolescents with PFP and highlight the high persistence rates. We need to discard the common misconception that PFP is 'self-limiting' and focus on how best to manage it.

\section{EXERCISE THERAPY MAY NOT BE FOR EVERYONE}

Exercise therapy is one of the mainstays of treating PFP. ${ }^{9-11}$ In an adolescent population, adding exercise therapy to patient education improved the recovery rates in both short term (3 months) and long term (24 months). However not all adolescents responded favourably to exercise therapy and the overall recovery rates was lower than what has been observed among adults. ${ }^{7}$

This suggests that exercise therapy is effective for some adolescents, but not all. So the question is how we can improve the effects of exercise therapy among adolescents to improve its outcomes? The key may be in an increased focus on managing training loads for the group of highly active adolescents with PFP. Importantly, frequent sports participation is a risk factor for persistent knee pain among young adolescents aged $12-15$ years and failure to modify sports participation could hinder recovery. ${ }^{12}$ This raises the question, does our current evidence-based approach have too much focus on exercise therapy and too little focus on training load management?

\section{ADHERENCE TO EXERCISES IS A CHALLENGE}

In our recent randomised trial on adolescent PFP, the majority of adolescents adhered poorly to the exercise programme. ${ }^{4}$ Those who did their home exercises three times per week or more were four times more likely to be recovered after 12 months compared with those with poor adherence $(<1$ exercise session per week). ${ }^{1}$ Adherence is vital, and requires greater understanding of the barriers and facilitators for good adherence. It is essential that the adolescents and the parents are educated about the importance of adherence and understand why the exercises are important.

\section{TAILORING MANAGEMENT AND FUTURE DIRECTIONS}

Training load management and exercise therapy is likely to be a part of successful treatment of adolescents with PFP; however, there are several areas that need further exploration. These include areas such as psychology, pain mechanisms and social support, which may all be specific to adolescents. The discussions at the Fourth International Patellofemoral Research Retreat in September 2015 ${ }^{10}{ }^{11}$ highlighted these issues. The consensus was that we need to consider the entire spectrum of the patellofemoral continuum, from PFP in adolescence to patellofemoral osteoarthritis, tailor treatment and avoid assuming that one size fits all.

\section{Competing interests None declared.}

Provenance and peer review Not commissioned; externally peer reviewed.
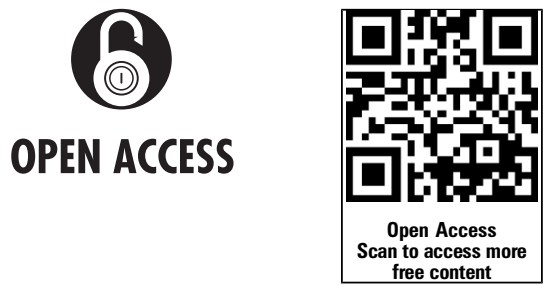

Open Access This is an Open Access article distributed in accordance with the Creative Commons Attribution Non Commercial (CC BY-NC 4.0) license, which permits others to distribute, remix, adapt, build upon this work non-commercially, and license their derivative works on different terms, provided the original work is properly cited and the use is noncommercial. See: http://creativecommons.org/licenses/ by-nc/4.0/

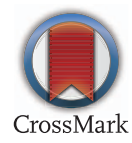

To cite Rathleff MS. Br J Sports Med 2016:50:831832

Accepted 4 May 2016

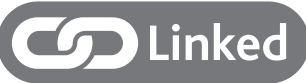

http://dx.doi.org/10.1136/bjsports-2016-096268 - http://dx.doi.org/10.1136/bjsports-2016-096384 
Br J Sports Med 2016;50:831-832.

doi:10.1136/bjsports-2016-096328

\section{REFERENCES}

1 Murray CJ, Richards MA, Newton JN, et al. UK health performance: findings of the Global Burden of Disease Study 2010. Lancet 2013;381: 997-1020.

2 Bjerrum L, Ertmann R, Jarbøl D, et al. Almen medicin. 1st edn. Danmark: Munksgaard, 2014.

3 Rathleff MS, Roos EM, Olesen JL, et al. High prevalence of daily and multi-site pain-a cross-sectional population-based study among 3000 Danish adolescents. BMC Pediatr 2013; 13:191.

4 Rathleff MS, Roos EM, Olesen JL, et al. Exercise during school hours when added to patient education improves outcome for 2 years in adolescent patellofemoral pain: a cluster randomised trial. Br J Sports Med 2015;49:406-12.

5 Molgaard C, Rathleff MS, Simonsen 0.

Patellofemoral pain syndrome and its association with hip, ankle, and foot function in 16- to 18-year-old high school students: a single-blind case-control study. J Am Podiatr Med Assoc 2011;101:215-22.

6 Myer GD, Ford KR, Barber Foss KD, et al. The incidence and potential pathomechanics of patellofemoral pain in female athletes. Clin Biomech 2010;25:700-7.

7 Rathleff MS, Vicenzino B, Middelkoop M, et al. Patellofemoral pain in adolescence and adulthood: same same, but different? Sports Med 2015;45:1489-95.

8 Rathleff MS, Rathleff CR, Olesen JL, et al. Is knee pain during adolescence a self-limiting condition? Prognosis of patellofemoral pain and other types of knee pain. Am J Sports Med 2016;44:1165-71.
9 van der Heijden RA, Lankhorst NE, van Linschoten R, et al. Exercise for treating patellofemoral pain syndrome. Cochrane Database Syst Rev 2015;1:CD010387

10 Crossley KM, Stefanik JJ, Selfe J, et al. 2016 Patellofemoral pain consensus statement from the 4th International Patellofemoral Pain Research Retreat, Manchester. Part 1: Terminology, definitions, clinical examination, natural history, patellofemoral osteoarthritis and patient-reported outcome measures. Br J Sports Med 2016;50:839-43.

11 Crossley KM, van Middelkoop M, Callaghan MJ, et al. 2016 Patellofemoral pain consensus statement from the 4th International Patellofemoral Pain Research Retreat, Manchester. Part 2: recommended physical interventions (exercise, taping, bracing, foot orthoses and combined interventions). Br J Sports Med 2016:50:844-52.

12 Rathleff $C R$, Olesen JL, Roos EM, et al. Half of 12-15-year-olds with knee pain still have pain after one year. Dan Med J 2013;60:A4725. 